\title{
4 Dimensions of neighborhood tracts and their associations with mental
}

\section{5 health problems}

6

8 Katherine L. Forthman ${ }^{1,2 \uparrow}$, Hung-wen Yeh $^{1 \&}$, Rayus Kuplicki ${ }^{1 \&}$, Martin P. Paulus ${ }^{1, \&^{*}}$

$12{ }^{1}$ Laureate Institute for Brain Research, Tulsa, OK

132 University of Tulsa, Tulsa OK

14

15 TThese authors contributed equally to this work.

$16 \&$ These authors also contributed equally to this work.

$19 *$ Correspondence to:

20 Martin P. Paulus M.D.

216655 S Yale Ave Tulsa, OK 74136-3326

22 mpaulus@laureateinstitute.org

23 Phone: 918502 5120, FAX: 9185025135 
bioRxiv preprint doi: https://doi.org/10.1101/518258; this version posted January 11,2019 . The copyright holder for this preprint (which was not certified by peer review) is the author/funder, who has granted bioRxiv a license to display the preprint in perpetuity. It is made available under aCC-BY 4.0 International license.

\section{Disclosures and acknowledgments}

26 None of the authors have conflicting equity ownership, profit-sharing agreements,

27 royalties, patents. Mrs. Forthman and Drs. Yeh, Kuplicki, and Paulus report no

28 competing interests. 


\section{Abstract}

\section{Objective -}

32 Neighborhood characteristics can have profound effects on resident health. The aim of

33 this study was to use an unsupervised learning approach to reduce the multi-dimensional

34 assessment of a neighborhood using American Community Survey (ACS) data to

35 simplify the assessment of neighborhood influence on health.

\section{Method -}

37 Multivariate quantitative characterization of the neighborhood was derived by performing

38 a factor analysis on the 2011-2015 ACS data. The utility of the latent variables was

39 examined by determining the association of these factors with poor mental health

40 measures from the 500 Cities Project 2017 release.

\section{Results -}

42 A five-factor model provided the best fit for the data and the latent factors quantified the

43 following characteristics of the census tract: (1) affluence, (2) proportion of singletons in

44 neighborhood, (3) proportion of African-Americans in neighborhood, (4) proportion of

45 seniors in neighborhood, and (5) proportion of noncitizens in neighborhood. African-

46 Americans $\left(R^{2}=0.67\right)$ in neighborhood and Affluence $\left(R^{2}=0.83\right)$ were strongly

47 associated with poor mental health.

\section{Conclusions -}

49 These findings indicate the importance of this factor model in future research focused on

50 the relationship between neighborhood characteristics and resident health. 


\section{Introduction}

53 There is strong evidence that certain characteristics of the neighborhood are associated

54 with both the physical and the mental health of its residents [1-7]. However, the strength

55 of this effect and the qualities of the neighborhood environment that are related to the

56 effect are unclear. Contradictory results in past studies relating neighborhood

57 characteristics and health indicate that the environmental effect remains elusive [8]. Thus,

58 objectively delineating the dimensions of a neighborhood and evaluating their

59 relationship to mental health could have important implications for future research

60 linking social factors to the biological processes underlying psychiatric disorders.

62 Past research has not yet fully elucidated the relationship between mental health and

63 neighborhood environment for several reasons. First, most studies only evaluate the

64 effects of one neighborhood characteristic — commonly neighborhood socioeconomic

65 status (NSES) or racial composition — rather than looking at a broader range of variables

66 describing the neighborhood. There is an emerging consensus that NSES is correlated

67 with physical and mental health, however the lack of more information about the nature

68 of this relationship leaves no hint of how NSES might be linked to these health effects.

69 Second, amidst the current literature are many different approaches in ascertaining a

70 population, extracting neighborhood measures, focusing on specific indices, or selecting

71 a subset of the population. A comprehensive approach has been lacking and could

72 provide a crucial step forward to identify specific environmental factors influencing rates

73 of poor mental health. 
75 The American Community Survey (ACS) a household survey conducted by the U.S.

76 Census. It covers a vast number of statistics and includes a substantial sample of the U.S.

77 population. Therefore, it is an ideal dataset for studying demographics. In order to use as

78 many of the statistics provided by the ACS as possible, we used a latent variable

79 approach to arrive at a multivariate quantitative characterization of the neighborhood.

80 This method gave us the opportunity to objectively select variables to include in our

81 analysis based on their contribution to the variance between neighborhoods. We assumed

82 that these statistics are linked by underlying, latent variables. This allowed us to work

83 with a smaller number of variables without sacrificing any data.

85 Few studies have used such a method for the characterization of neighborhoods. Miles et

86 al. describes a method for measuring NSES using factor analysis and the ACS that can be

87 explored longitudinally [9]. Their method aims to find significant neighborhood

88 characteristics based on factor invariance. Another study by Li et al. combines factor

89 analysis and cluster analysis for a multivariate-structural approach to characterizing

90 neighborhoods [10]. These studies were used as a template for the method described in

91 this paper. This study aimed to use a latent variable approach to identify factors that

92 comprehensively quantify the neighborhood characteristics. We used the 2011-2015 ACS

93 data and applied a factor analysis method after appropriately transforming selected

94 variables. Moreover, we examined the influence of these latent variables on mental health

95 by comparing the factors to data from the 500 Cities project 2017 release [11]. The 500-

96 cities dataset includes 27,199 tracts. We performed this analysis in order to explore if one

97 or more factors would be significantly associated with proportion of individuals in a 
98 neighborhood with at least 14 "bad mental health days" as ascertained by the Centers for

99 Disease Control and Prevention (CDC).

\section{Methods}

\section{Sample}

103 Neighborhood data were obtained from the ACS. The ACS is a national survey that uses

104 continuous measurement methods based on a series of monthly samples to produce

105 annual estimates for the same small areas (census tracts and block groups). The ACS was

106 inaugurated in 2005. Each year, 3.54 million addresses are surveyed across the country.

107 This sample is sufficient to provide reliable 1-year estimates for geographical areas with

108 a population greater than 65,000 ; for areas with smaller populations, the sample needs be

109 accumulated over several years to achieve reliable estimates (3-year and 5-year estimates

110 for areas with population larger than and no more than 20,000, respectively) [12]. In this

111 study, neighborhood data were obtained at tract-level from the 5-year estimate spanning

112 2011-2015 [13].

113

114 This study aimed to use data at the smallest geographic division possible for a fine-

115 grained view of living environment. The two smallest geographic divisions available in

116 the ACS dataset are block-groups and tracts. On average, a block group is $1 / 3$ the size of

117 a tract. The factor analysis was performed on both levels and the resulting factors were

118 largely the same (Comparison to Block Group, Supplementary Methods). Though larger,

119 the tract level factors were chosen because there were variables of interest that were not 
120 available at the block group level (Fig S1). These variables included disability status,

121 citizenship status, and mobility. Additionally, the tract-level factors have a smaller

122 margin of error.

123

124 There are 72,424 census tracts in the United States that are within city and state

125 boundaries. Tracts consist of areas with a population between 1,200 and 8,000

126 individuals, are primarily defined by population density, and are delineated by visibly

127 identifiable features, such as highways, roads, or rivers. Both home addresses and group

128 quarters were sampled from the tracts. Group quarters are places where a group of people

129 live together in a place which is owned or managed by an entity that provides housing or

130 services to residents; for example, nursing homes, college dormitories, and homeless

131 shelters are all group quarters. Approximately $2.5 \%$ of the expected population inhabiting

132 group quarters was sampled [12].

\section{Data extraction and variable selection}

135 ACS variables are organized into tables, which are organized by content and format [14].

136 Not all tables were used in this analysis. A description of the excluded tables and the

137 reason for exclusion is provided in the supplementary material (Table S1). 37 tables were

138 included in the analyses and contained 461 measures describing tract characteristics of

139 age, race/ethnicity, citizenship, nativity, mobility, means of transportation to work,

140 household type, marriage status, education level, disability status, income, employment

141 status, home type, housing cost, and residential tenure. Among these 461 measures, 215

142 were removed due to redundancy or low variability. Redundancy was defined as 
143 variables that were sufficiently represented by another variable (for example, the female

144 population is redundant because it is the inverse of the male population). Low variablility

145 was defined as a low coefficient of variation across tracts. A flow chart explaining how

146 the dataset was reduced is given in Fig S2. The remaining 246 statistics describing strata

147 or subgroups (e.g. age groups, gender, education levels) of a tract were combined to form

148 single statistics (Feature Selection, Supplementary Methods). This selection process led

149 to a final number of 39 measures for subsequent analyses.

151 These measures were subjected to a heuristic, data-driven transformation approach to

152 approximate Gaussian distributions as close as possible (Transformation, Supplementary

153 Methods). Missing values were imputed by the weighted average of 10-nearest neighbors

154 after transformation.

\section{Factor analysis}

157 A total of 39 transformed and/or imputed measures were then entered into an exploratory

158 factor analysis to investigate the underlying latent variable structure. Factor loadings

159 were estimated by the minimum residual method, and oblimin rotation was applied to

160 improve interpretation. We explored a range between 1 and 12 factors and chose the

161 factor number based on Kaiser's rule (i.e. keeping factors with eigenvalues at least 1), a

162 scree plot, the amount of total variance explained from each model produced, and the

163 interpretability of the factor structure. The chosen factor model is depicted in Fig 1 . The

164 factor structures of the 4- and 6-factor models are shown in Figs S3 and S4 for

165 comparison purposes. The stability of the final factor model was examined by 2,000 
166 bootstrapped samples and the standard error was calculated for each loading of each

167 variable within each factor. Finally, the factor scores were computed for all U.S. tracts.

169 Fig 1. The Factor Structure. Each circular barplot is a visual representation of a single

170 latent factor. The name of the factor is in the center of the plot. Each bar represents the

171 loading of an input variable to the factor. Blue bars indicate a positive loading, while pink

172 bars indicate a negative loading. Variables with loadings $>0.3$ to the factor are

173 highlighted. Input variables are grouped by type with the colored lines around the edge of

174 each plot. These groups (starting from the top, moving clockwise) encompass age, race

175 and ethnicity, nativity and citizenship, mobility, transportation to work, household type,

176 marital status, education level, disability status, income, employment, residential

177 conditions, and tenure. A larger version of these plots is given in the supplement (S2).

179 Relationship between neighborhood latent variables and

\section{0 mental health}

181 The factor scores for each census tract were merged with data from the 500 Cities

182 Project, which provides tract-level mental health data for 27,204 tracts [11]. This project

183 used Small Area Estimation (SAE) to estimate prevalence of health issues. The SAE was

184 performed on datasets managed by the CDC, including the Behavioral Risk Factor

185 Surveillance System (BRFSS) [15]. The BRFSS was conducted by a telephone survey

186 interviewing approximately 400,000 adults across the United States and its territories

187 [16]. Iterative proportional fitting was used to weight statistics by age, gender, race and

188 ethnicity, and geographical region [17]. For the purposes of this study, we focused on 
189 only one question in the BRFSS: "Now thinking about your mental health, which includes

190 stress, depression, and problems with emotions, for how many days during the past 30

191 days was your mental health not good?" The tract-level SAE from this question provided

192 an estimate of the proportion of individuals $\geq 18$ years old within a tract who responded

193 that they had $\geq 14$ bad mental health days. These estimates were linked to the

194 neighborhood factor scores and their associations were investigated descriptively by

195 smoothing splines.

\section{Software}

198 The statistical software R [18] was used for all data extraction, analyses, and the

199 generation of all figures. The R code for this manuscript is available as a supplement.

200 ACS data were obtained through the R package acs [19]. The e1071 (31) and scales (32)

201 packages were used for transformation, the $D M w R$ package for imputation, and the psych 202 package [20] for factor analysis.

\section{Results}

\section{Exploratory factor analysis}

206 The scree plot shows that a factor model with up to eight factors had eigenvalues greater

207 than 1.0 and an 'elbow' at 5 factors (Fig S5). Together, these factors accounted for 60\%

208 of the variance and reproduced 0.98 of the off-diagonal elements of the sample

209 correlation matrix, and 0.04 root-mean square of residuals (RMS). Fit statistics of the 12

210 factor models explored are given in Table S2. The five factors were labeled based on the 
211 variables with the strongest absolute loadings as: (1) Affluence, (2) Singletons in Tract,

212 (3) African-Americans in Tract, (4) Seniors in Tract, and (5) Noncitizens in Tract (Fig

213 S6). Affluence, which accounted for $16 \%$ of the variance, showed greatest loadings from

214 tract statistics relating to NSES, such as income ( 0.79 for Income in the circle plot) and

215 education (0.73 for Education). Singletons in Tract, which accounted for $13 \%$ of the

216 variance, demonstrated strong loadings from the proportion of people living alone $(0.81$

217 for Lives.alone), the average number of housing units per structure ( 0.72 for

218 Units.in.structure), and the proportion of homes in a tract not occupied by their owner

219 (0.70 for Not.owner.occupied). African-Americans in Tract, which accounted for $11 \%$ of

220 the variance, was positively correlated with the proportion of black population ( 0.87 for

221 Black) and inversely correlated with the proportion of white population ( -0.87 for White).

222 This factor was also highly correlated to proportion of single moms ( 0.69 for

223 Single.moms), a lack of married couple family homes (-0.49 for Married.spouse.present,

2240.46 for Never.married), the unemployed population ( 0.49 for Unemployed), and the

225 proportion of people living on government assistance ( 0.37 for w.SSI, 0.34 for w.PAI).

226 Seniors in Tract, which accounted for $11 \%$ of the variance, was primarily related to age

227 (0.85 for Age) and the proportion of the population receiving Social Security Income

228 (0.87 for w.Social.Security). Noncitizens in Tract, which accounted for $9 \%$ of the

229 variance, was strongly related to the proportion of certain racial and ethnic minorities

230 (0.74 for Some.other.race, 0.83 for Hispanic.or.Latino) as well as the population of U.S.

231 citizens (0.76 for Not.US.citizen).

233 The oblique rotation procedure left the factors correlated (Fig S7): African-Americans in 
234 Tract was correlated with Noncitizens in Tract $(r=0.36)$, Singletons in Tract $(r=0.33)$,

235 and Affluence $(r=-0.29)$; Seniors in Tract was correlated with Noncitizens in Tract $(r=$ -

236 0.26) and Affluence $(\mathrm{r}=-0.21)$. Least correlated were Noncitizens in Tract and Affluence

$237 \quad(\mathrm{r}=-0.08)$.

239 Associations between neighborhood factors and prevalence of

240 poor mental health

241 The prevalence of individuals in a tract with 14 or more days of bad mental health

242 appeared to be most related to Affluence, followed by African-Americans in Tract,

243 Noncitizens in Tract, Singletons in Tract, and least related to Seniors in Tract (Fig 2).

244 There was an obvious inverse relationship between the bad mental health measure and

245 affluence of tracts for all states (median R-square 0.83 and inter-quartile range (IQR)

246 between 0.80 and 0.86 , Fig S8). There also existed monotone, increasing trends between

247 the health measure and the two factors African-Americans in Tract (median and IQR $R^{2}$ :

$2480.67(0.58,0.74))$ and Noncitizens in Tract (median and IQR $\left.R^{2}: 0.49(0.35,0.67)\right)$,

249 despite higher variability in trends across states for the latter. Concave trends appeared

250 between the bad mental health outcome and Singletons in Tract for most states (median

251 and IQR $\left.R^{2}: 0.17(0.11,0.24)\right)$. The uniform relationship for tracts with a lower

252 Singletons in Tract score indicates that neighborhoods with fewer singletons tend to have

253 lower rates of poor mental health. As the factor score increases, however, rates of mental

254 health become more variable, indicating there is no relationship between mental health

255 and a higher Singletons in tract score. Seniors in Tract showed different patterns across 
256 states, with a mixture of positive and negative, linear and concave trends (median and

257 IQR $\left.R^{2}: 0.05(0.02,0.11)\right)$.

258

259 Fig 2. Relationship Between Factors and Mental Health. Proportion of residents over 18 who

260 have experienced $\geq 14$ days of bad mental health during the past 30 days from the 500 Cities

261 Project vs. neighborhood factor scores. Each point on the plot represents a single tract. A separate

262 cubic spline (colored curve) was fit to tracts of each state.

263

\section{Discussion}

265 This study aimed to quantify neighborhood characteristics using a latent variable

266 approach performed on census data and to determine the utility of these latent variables

267 by relating them to mental health outcomes. There were two main results. First, five

268 factors, Affluence, Singletons in Tract, African-Americans in Tract, Seniors in Tract, and

269 Noncitizens in Tract, accounted for $60 \%$ of the neighborhood tract variance and provided

270 a multidimensional assessment of census tracts. Second, two of the five factors were

271 shown to be strongly related to tract-level descriptors of poor mental health: Affluence,

272 and African-Americans in Tract. Taken together, this study shows that census tracts can

273 be robustly quantified using five dimensions and that some of these latent variables are

274 strongly associated with tract-level mental health status.

276 Several studies have described the relationship between neighborhood characteristics and

277 mental health $[8,21,22]$. However, to our knowledge, no previous study has used a

278 factor analysis approach to extract a multi-dimensional set of latent variables for the 
279 characterization of neighborhoods. A recent study by Hu et al. was published showing the

280 relationship between NSES and health [23]. However, the results of these analyses are

281 limited because- as in many other papers- only NSES was examined as a predictor of

282 health while the possible influence of other neighborhood characteristics was ignored.

283 Additionally, the Area Deprivation Index (ADI) used in this paper, developed by Singh

284 [24], was developed based on a single-factor analysis using 17 socioeconomic indicators

285 selected by Singh from the 1990 U.S. census, however time-invariance of the results of

286 the factor analysis was not tested. It is important that this statistic was not tested for time-

287 invariance, as assuming the factor structure is consistent over time may lead to biased

288 results if time invariance of the factor structure does not hold [25]. An index should be

289 based on data in the relevant time period if time-invariance has not been demonstrated. A

290 factor model can be easily calculated for any 5-year period after 2005 using the methods

291 we describe in this paper.

292

293 Our results indicate that our factors representing Affluence and African-Americans in

294 Tract are most predictive of mental health rates in a neighborhood. Furthermore, results

295 indicate the pattern each relationship follows. The relationship between African-

296 Americans in Tract and mental health appears linear, while the relationship between

297 Affluence and mental health appears to follow an exponential decay. Our four most

298 explanatory factors (Affluence, African-Americans in Tract, Singletons in Tract, and

299 Noncitizens in Tract), have all been explored to some extent in past research. Affluence

300 appears to be synonymous with such measures as socioeconomic status, economic

301 disadvantage, and neighborhood deprivation as described in several previous studies [8]. 
302 African-Americans in Tract and Noncitizens in Tract have also been explored in a few

303 past studies as 'racial congruence' or 'ethnic diversity', etc. [8]. Even Singletons in Tract

304 is representative, to an extent, of residential mobility or neighborhood stability [8]. The

305 only factor not explored in previous studies was the elderly population, which we have

306 shown to be uncorrelated with rates of mental health. The relationship of our factors to

307 interests of previous studies indicate that our factors are intuitively as well as objectively

308 descriptive of neighborhoods.

310 Limitations

311 The variables used in this study were limited to those collected by the U.S. census.

312 Consequently, there are some neighborhood characteristics shown in previous studies to

313 be related to mental health that are not included in this study. For example, this study

314 does not include walkability, neighborhood disorder, social factors, neighborhood

315 hazards, the built environment, or the service environment [8]. Even with these

316 limitations, the ACS dataset serves as a reliable source for neighborhood statistics. These

317 statistics include responses from millions of households across the U.S., the data are

318 collected consistently over time, and the statistics cover a broad range of characteristics.

319 Additionally, neighborhood characteristics based on subjective resident response may be

320 biased and misleading. For example, perception of neighborhood conditions has been

321 shown to be significantly correlated to rates of depression [8], but there is no assurance

322 that this relationship does not simply depict the poor outlook of those with depression. 
324 Additionally, there exist some challenges from an analysis standpoint. The indeterminacy

325 problem is a well-known issue with factor analysis [26, 27]. Factor analysis results in

326 factors that must be subjectively defined. This has always been a fundamental problem of

327 factor analysis. However, the circle plots clearly depict what the factors represent.

328 Additionally, this problem is superseded by the utility of the latent variables over the raw

329 data. The latent variable structure, though vague, simplifies interpretability drastically.

\section{$331 \quad$ Future directions}

332 The influence of these factors at an individual level is still unknown. Jones et al. make a

333 point that people experience substantial segregation across a range of spaces, such as

334 areas of work or recreation, in their daily lives [28]. The extent to which an individual's

335 neighborhood characteristics affect their mental health must be explored in future

336 longitudinal studies.

338 The 500-Cities data contains data on physical health as well as mental health. An

339 exploration on the relationship between the factors and the other statistics in the 500-

340 Cities dataset is given in Fig S9. It is clear from this plot that the factors relate to more

341 than just mental health.

343 Conclusion

344 Neighborhood factors based on census data provide comprehensive, objectively derived

345 neighborhood characteristics. To our knowledge, our work takes into consideration a

346 variety of neighborhood statistics not previously explored, while remaining simple and 
bioRxiv preprint doi: https://doi.org/10.1101/518258; this version posted January 11,2019 . The copyright holder for this preprint (which was not certified by peer review) is the author/funder, who has granted bioRxiv a license to display the preprint in perpetuity. It is made available under aCC-BY 4.0 International license.

347 highly interpretable. We intend that these factors may be used to further explore the

348 relationship between living environment and mental health. Our findings show that

349 neighborhood characteristics are strongly related to mental health, indicating the

350 importance of the factor model in future research focused on the influence of

351 neighborhood characteristics on mental health. 


\section{References}

354 1. Caughy, M.O.B., P.J. O’Campo, and C. Muntaner, When being alone might be

355 better: neighborhood poverty, social capital, and child mental health. Social science \&

356 medicine, 2003. 57(2): p. 227-237.

357 2. Barnes, J., et al., Neighborhood characteristics and mental health: the relevance

358 for mothers of infants in deprived English neighborhoods. Social psychiatry and

359 psychiatric epidemiology, 2011. 46(12): p. 1243-1249.

$3603 . \quad$ Van Dyck, D., et al., Relationship of the perceived social and physical

361 environment with mental health-related quality of life in middle-aged and older adults:

362 mediating effects of physical activity. PloS one, 2015. 10(3): p. e0120475.

363 4. Edwards, B. and L.M. Bromfield, Neighbourhood influences on young children's

364 emotional and behavioural problems. Family Matters, 2010(84): p. 7.

365 5. Chi, G.C., et al., Individual and Neighborhood Socioeconomic Status and the

366 Association between Air Pollution and Cardiovascular Disease. Environ Health Perspect,

367 2016. 124(12): p. 1840-1847.

368 6. Moore, K.A., et al., Neighborhood Social Resources and Depressive Symptoms:

369 Longitudinal Results from the Multi-Ethnic Study of Atherosclerosis. J Urban Health,

$370 \quad$ 2016. 93(3): p. 572-88.

371 7. Rudolph, K.E., et al., Neighborhood disadvantage in context: the influence of

372 urbanicity on the association between neighborhood disadvantage and adolescent

373 emotional disorders. Soc Psychiatry Psychiatr Epidemiol, 2014. 49(3): p. 467-75. 
374 8. Mair, C.F., A.V. Diez Roux, and S. Galea, Are Neighborhood Characteristics

375 Associated with Depressive Symptoms? A Critical Review. Journal of Epidemiology and

376 Community Health, 2008.

377 9. Miles, J.N., et al., Constructing a Time-Invariant Measure of the Socio-economic

378 Status of U.S. Census Tracts. Journal of Urban Health, 2016. 93(1): p. 213-232.

379 10. Li, Y.-S. and Y.-C. Chuang, Neighborhood Effects on an Individual's Health

380 Using Neighborhood Measurements Developed by Factor Analysis and Cluster Analysis.

381 Journal of Urban Health : Bulletin of the New York Academy of Medicine, 2009. 86(1):

382 p. $5-18$.

383 11. Centers for Disease Control and Prevention, 500 Cities: Local Data for Better

384 Health, 2017 release. 2017, National Center for Chronic Disease Prevention and Health

385 Promotion, Division of Population Health.

386 12. Torrieri, N., et al., American Community Survey Design and Methodology. 2014,

387 U.S. Census Bureau.

388 13. https://www.census.gov/data.html

389 14. Bureau, U.S.C. American Community Survey (ACS): Table IDs Explained. March

390 14, 2017; Available from: https://www.census.gov/programs-

391 surveys/acs/guidance/which-data-tool/table-ids-explained.html.

392 15. Zhang, X., et al., Validation of Multilevel Regression and Poststratification

393 Methodology for Small Area Estimation of Health Indicators From the Behavioral Risk

394 Factor Surveillance System. American Journal of Epidemiology, 2015. 182(2): p. $127-$

395137. 
396 16. About BRFSS. 2014 May 16; Available from:

397 https://www.cdc.gov/brfss/about/index.htm.

398 17. BRFSS Frequently Asked Questions. 2018 January 2; Available from:

399 https://www.cdc.gov/brfss/about/brfss_faq.htm.

400 18. R Core Team, R: A Language and Environment for Statistical Computing. 2017,

401 R Foundation for Statistical Computing: Vienna, Austria.

402 19. Glenn, E.H., acs: Download, Manipulate, and Present American Community

403 Survey and Decennial Data from the US Census. 2017.

404 20. Revelle, W., psych: Procedures for Psychological, Psychometric, and Personality

405 Research. 2017, Northwestern University: Evanston, Illinois.

406 21. Kelley-Moore, J.A., et al., Do Local Social Hierarchies Matter for Mental

407 Health? A Study of Neighborhood Social Status and Depressive Symptoms in Older

408 Adults. J Gerontol B Psychol Sci Soc Sci, 2016. 71(2): p. 369-77.

409 22. Mair, C., et al., Change in neighborhood environments and depressive symptoms

410 in New York City: the Multi-Ethnic Study of Atherosclerosis. Health Place, 2015. 32: p.

$41193-8$.

412 23. Hu, J., A.J.H. Kind, and D. Nerenz, Area Deprivation Index Predicts Readmission

413 Risk at an Urban Teaching Hospital. American Journal of Medical Quality. 0(0): p.

4141062860617753063.

415 24. Singh, G.K., Area deprivation and widening inequalities in US mortality, 1969-

416 1998. American journal of public health, 2003. 93(7): p. 1137-1143.

417 25. Borsboom, D., When Does Measurement Invariance Matter? Medical Care, 2006.

418 44(11): p. S176-S181. 
bioRxiv preprint doi: https://doi.org/10.1101/518258; this version posted January 11,2019 . The copyright holder for this preprint (which was not certified by peer review) is the author/funder, who has granted bioRxiv a license to display the preprint in perpetuity. It is made available under aCC-BY 4.0 International license.

419 26. Bollen, K.A., Latent Variables in Psychology and the Social Sciences. Annual

420 Review of Psychology, 2002. 53(1): p. 605-634.

421 27. Steiger, J.H., Factor indeterminacy in the 1930's and the 1970's some interesting

422 parallels. Psychometrika, 1979. 44(2): p. 157-167.

423 28. Jones, M. and A.R. Pebley, Redefining Neighborhoods Using Common

424 Destinations: Social Characteristics of Activity Spaces and Home Census Tracts

425 Compared. Demography, 2014. 51(3): p. 727-752.

426 
Chose to use only Detailed Tables

There are 1045 Detailed Tables in the 2015 ACS dataset.

There are two kinds of detailed tables - Base and Collapsed. Collapsed tables have a lower level of detail. The Collapsed tables were not used.

Removed tables of certain subjects.

Some tables are race iterated - indicated by the letter after the table name. All of these tables were removed.

Some tables are available for Puerto Rico only. These tables were removed.

Chose tables representative of each subject.

Within the 37 tables are 461 statistics.

Statistics that were redundant were removed.

Statistics with a low coefficient of variance were removed.

Statistics were concatenated. 


\section{Scree Plot}

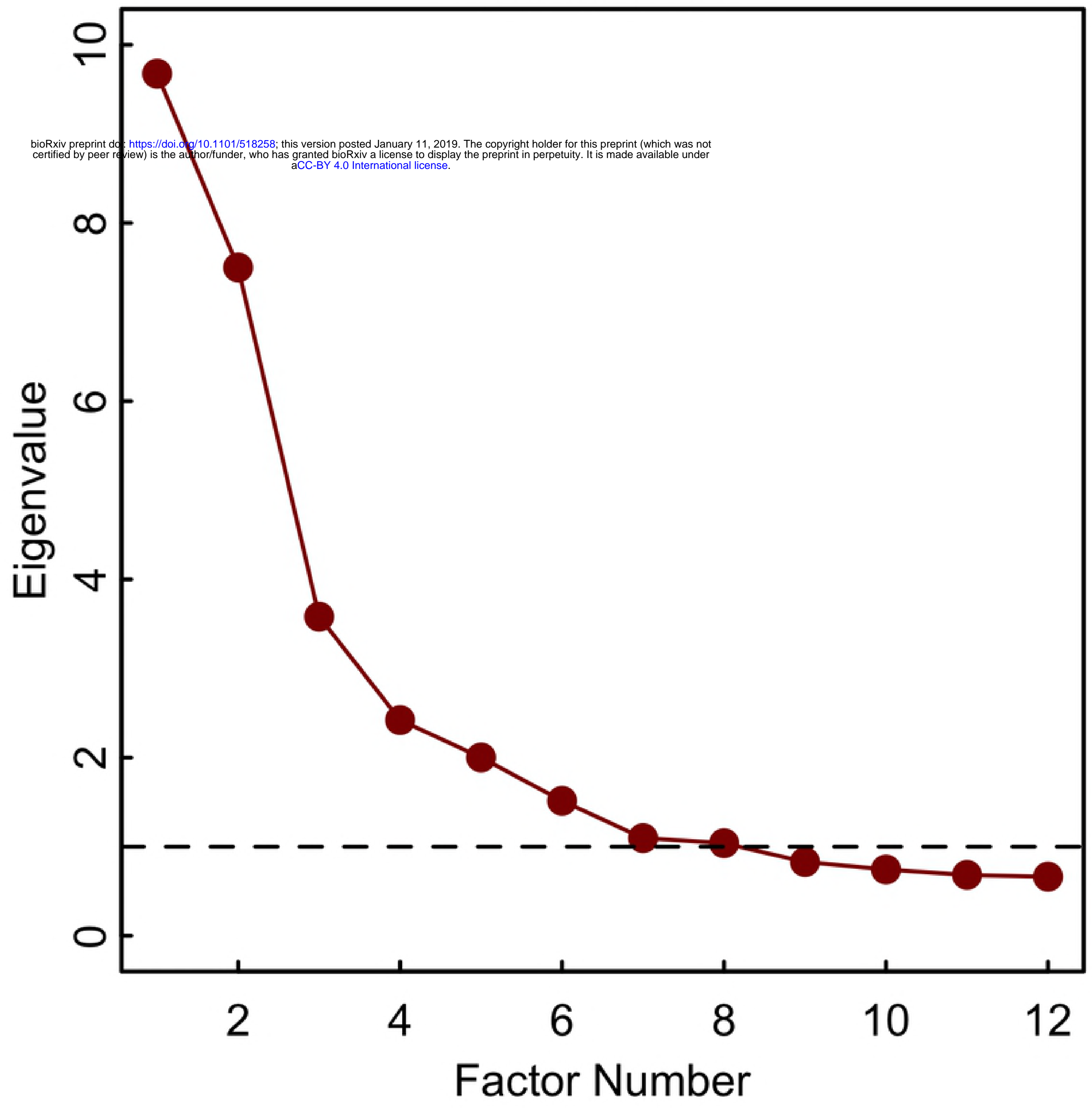

Fig S5 


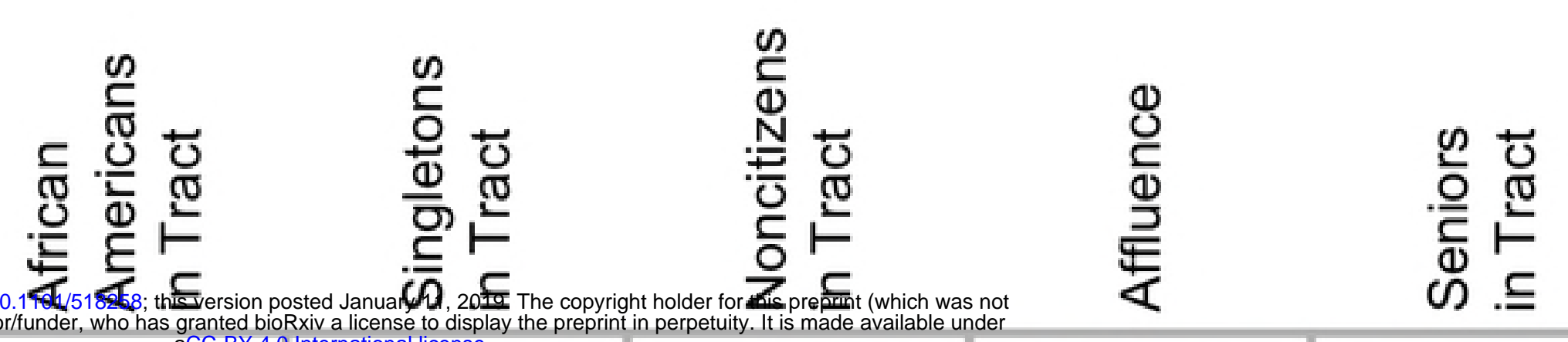

bioRxiv preprint doi: https://doi.org/10.1
certified by peer review) is the author/funder, who has granted bioRxiv a license to display the preprint in perpetuity. It is made available under

African

Americans in Tract

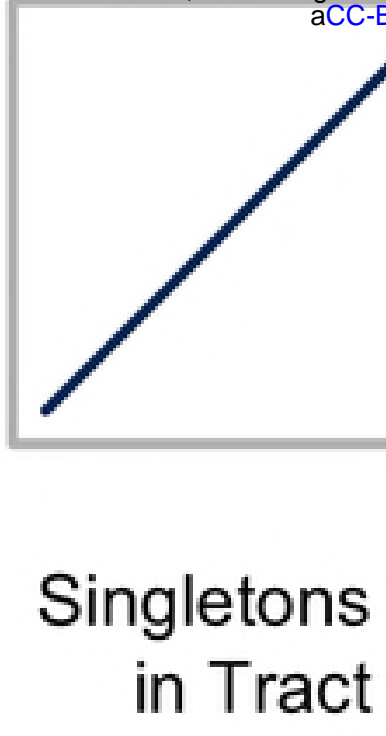

Noncitizens in Tract

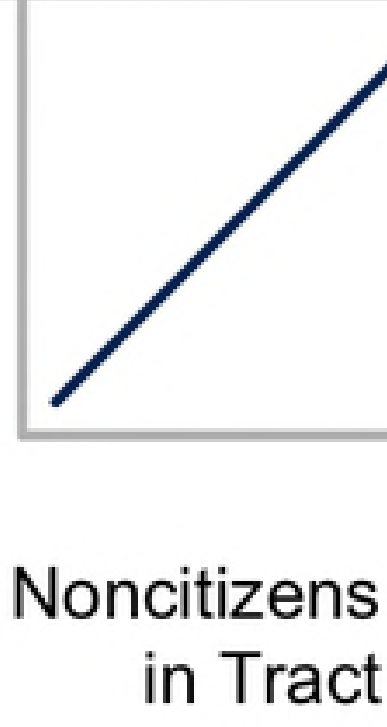

Affluence

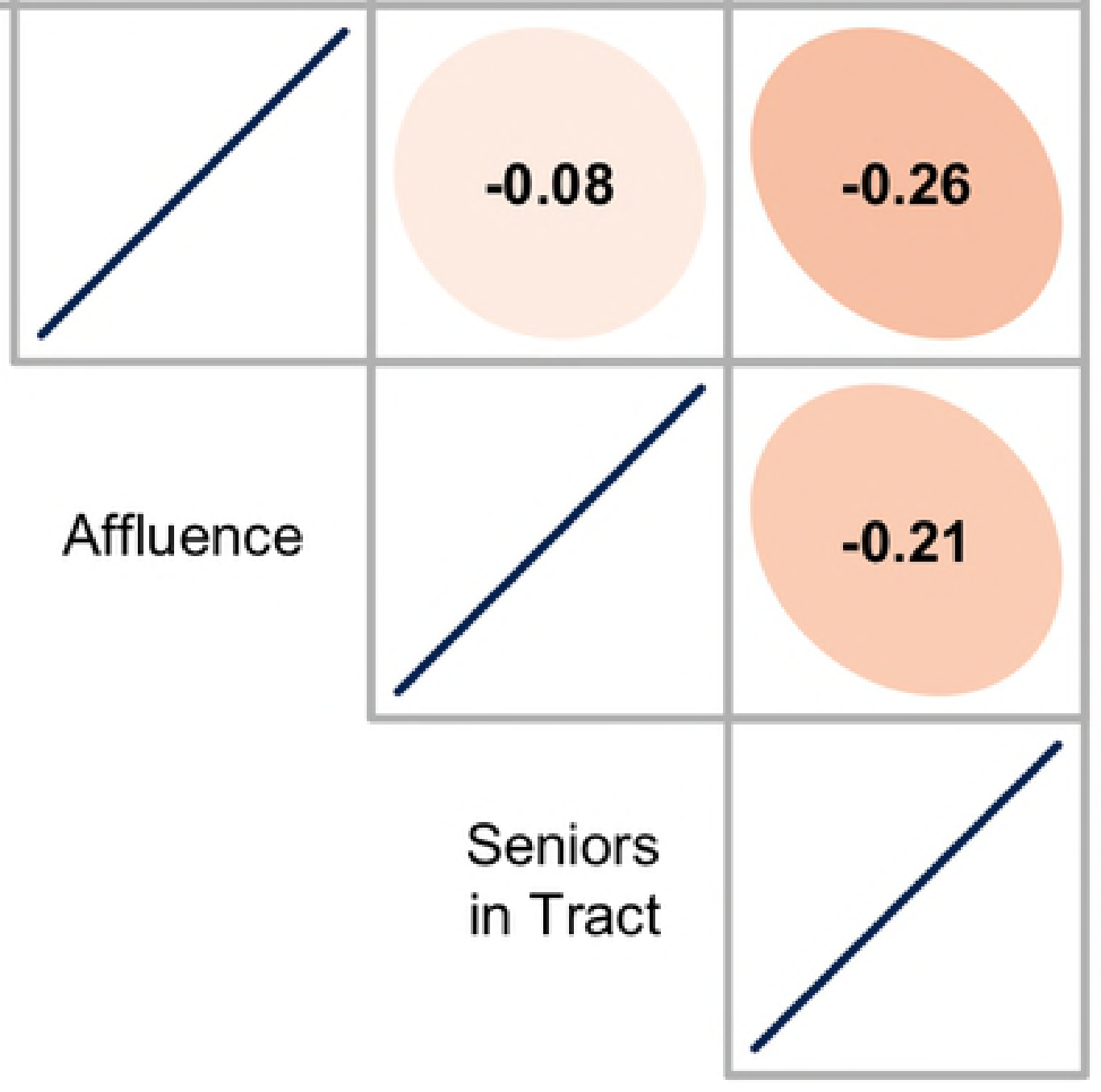



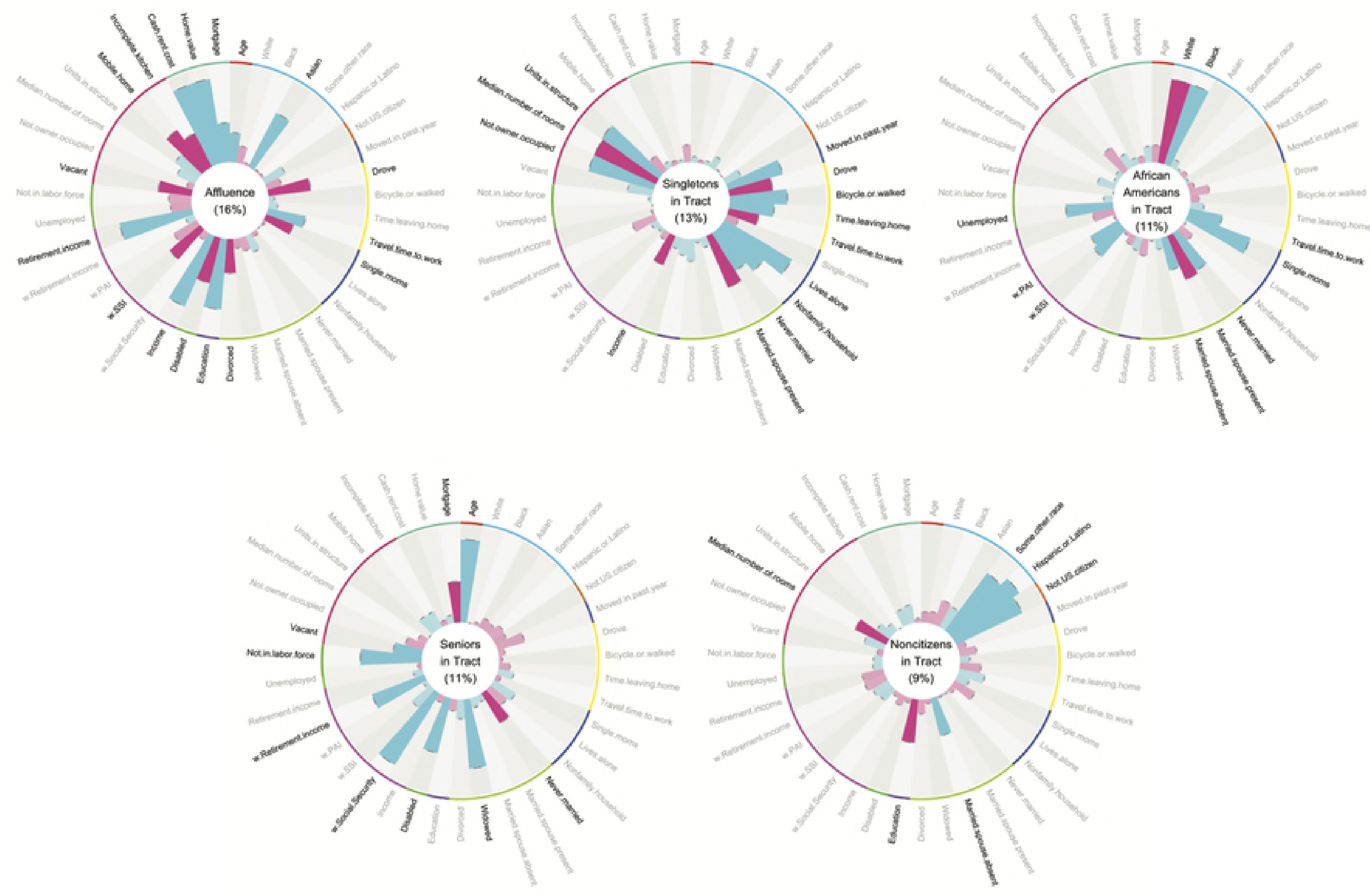

Fig 1 

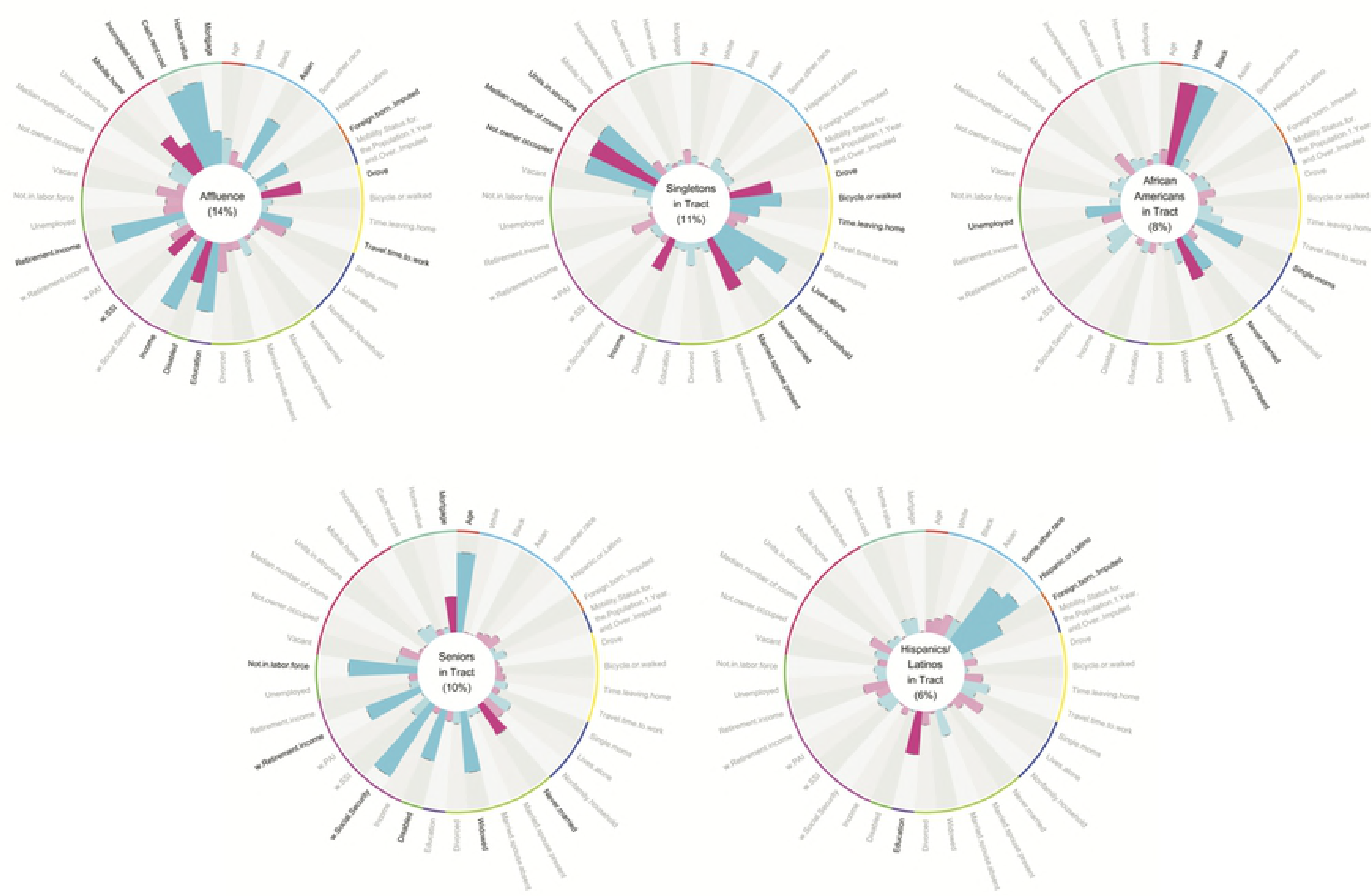

Fig S1 


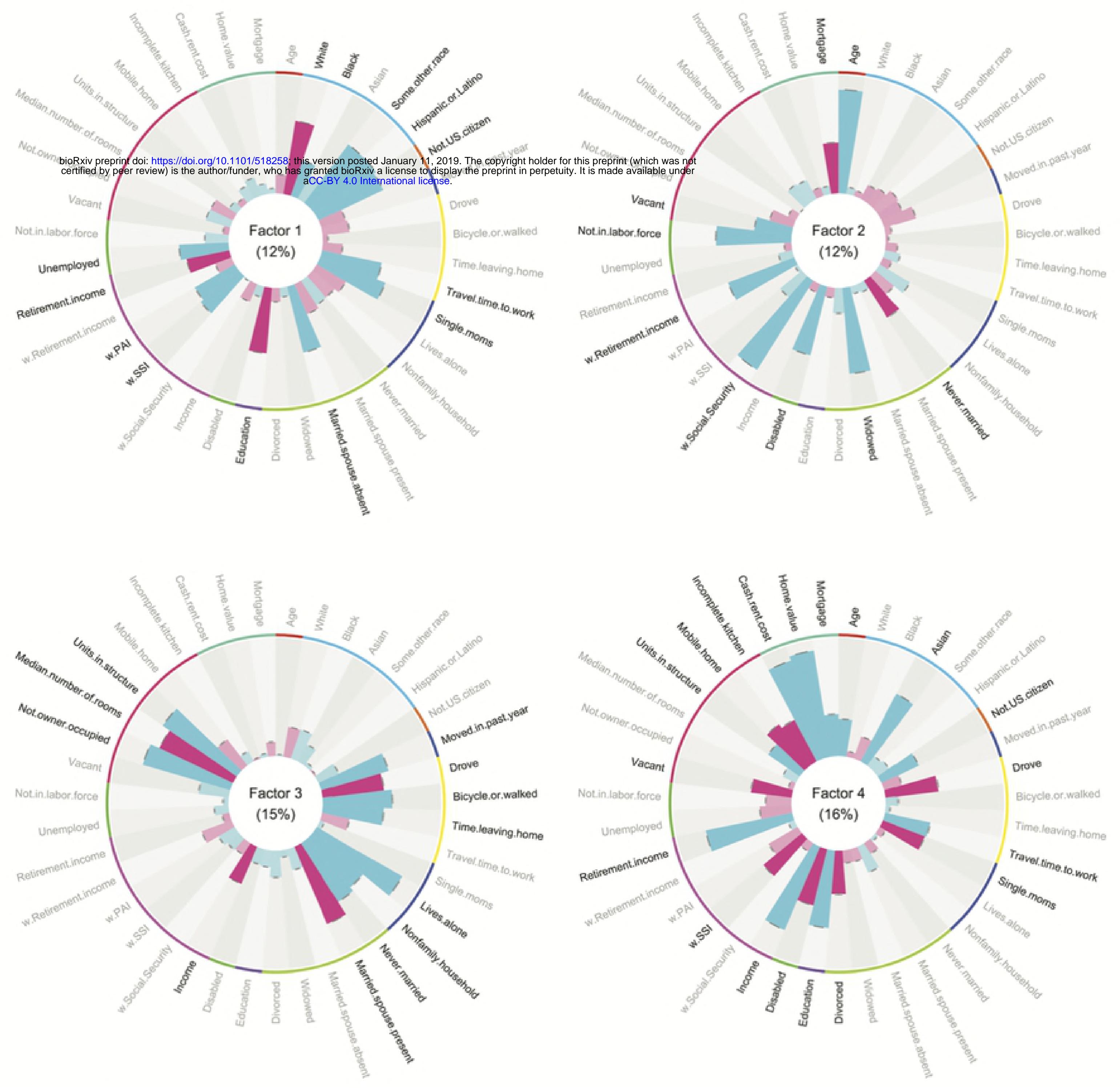

Fig S3 

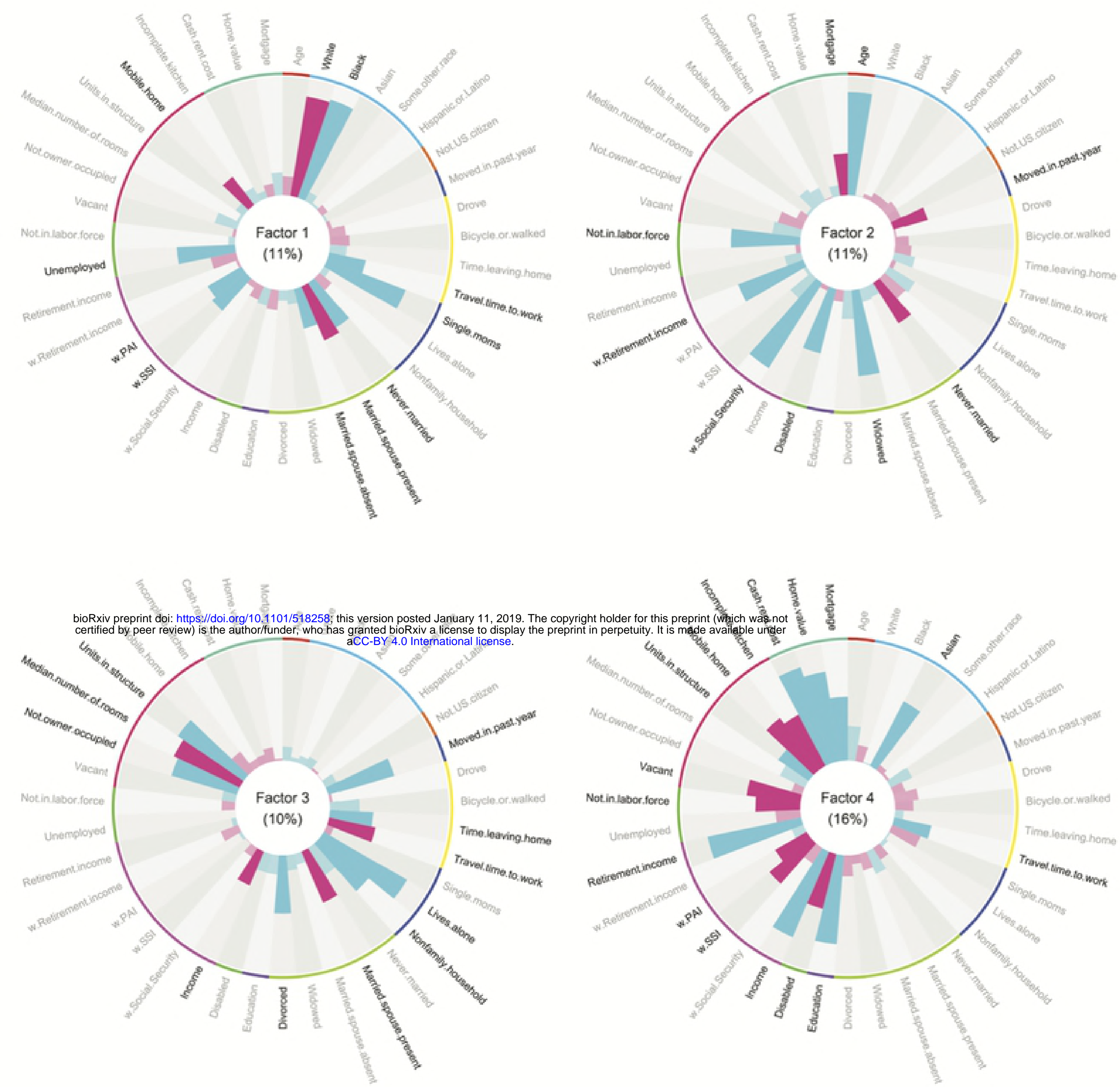

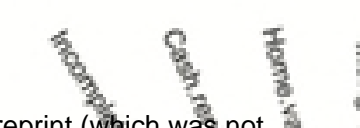
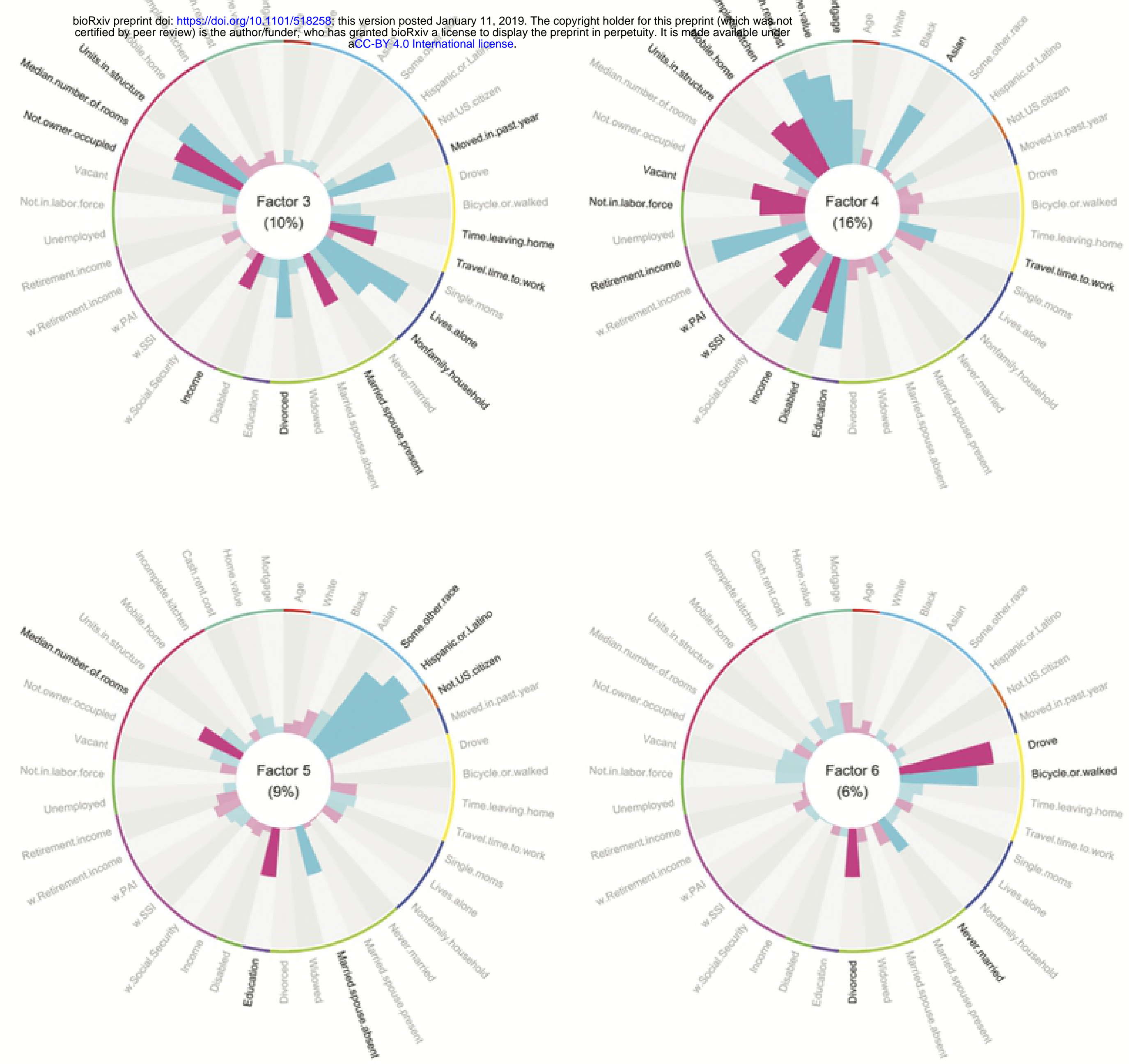

Fig S4 


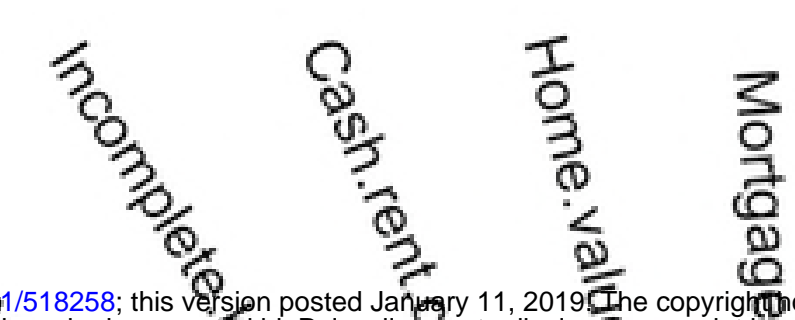

일

๑) certified by peer review) is the author/funder, who has granteg, bioRxiv a licease to display (tDe preprint in perpetuity. It is made available under

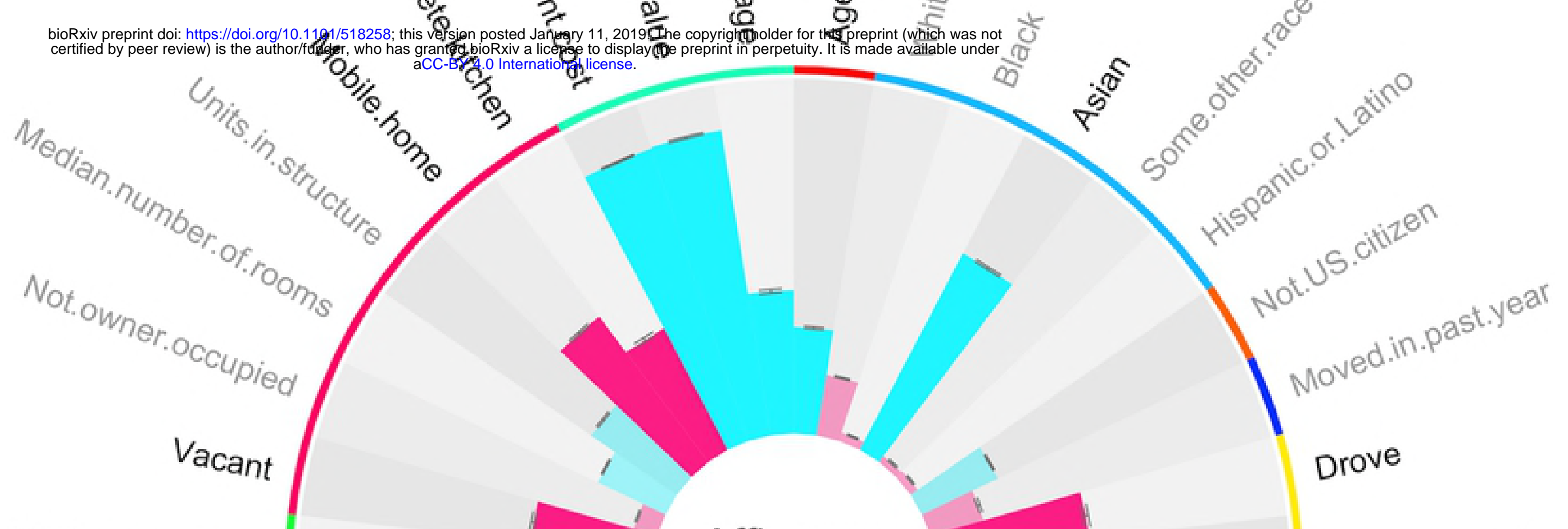

Not.in.labor.force Affluence

(16\%)

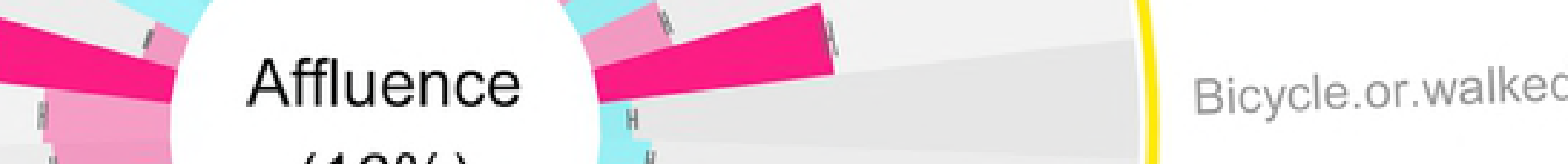

Retirementincome

Unemployed w. Retirementinc

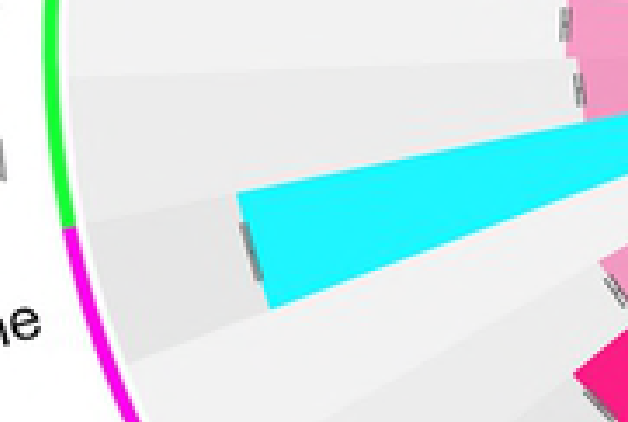

(n)
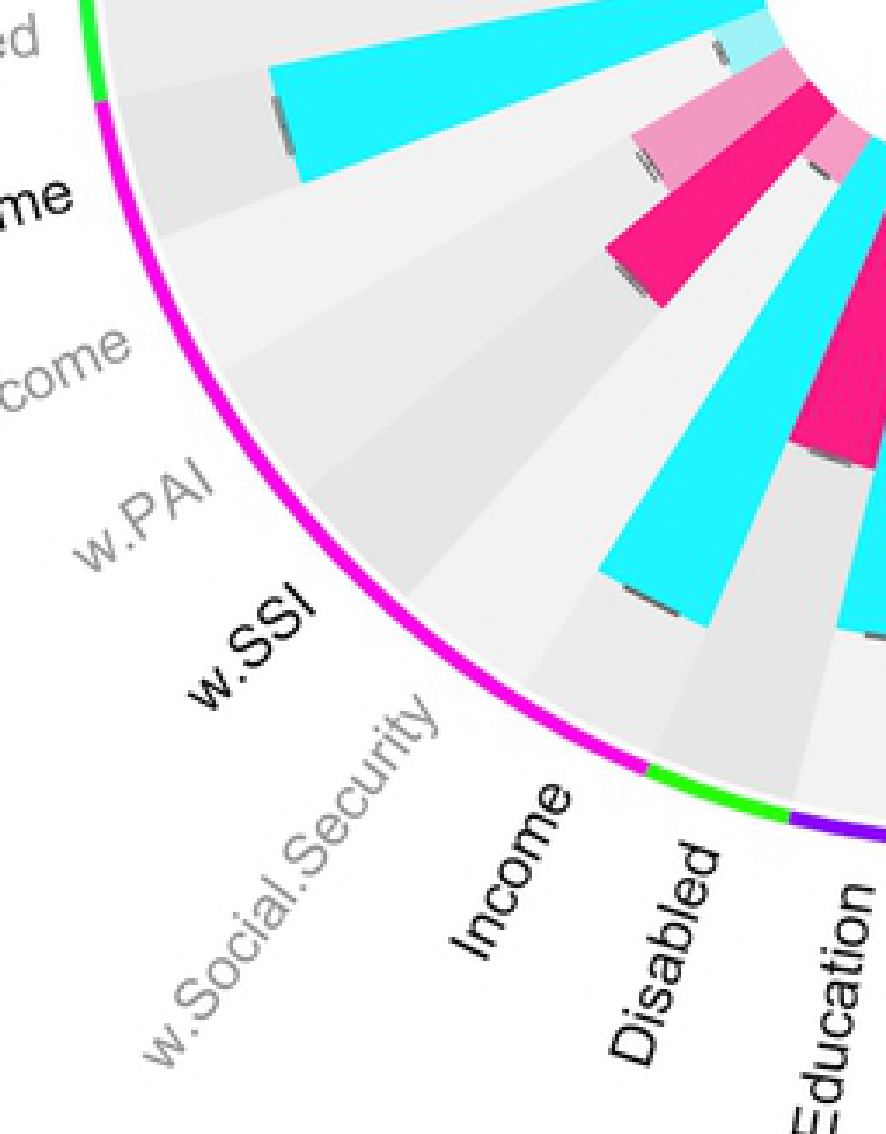


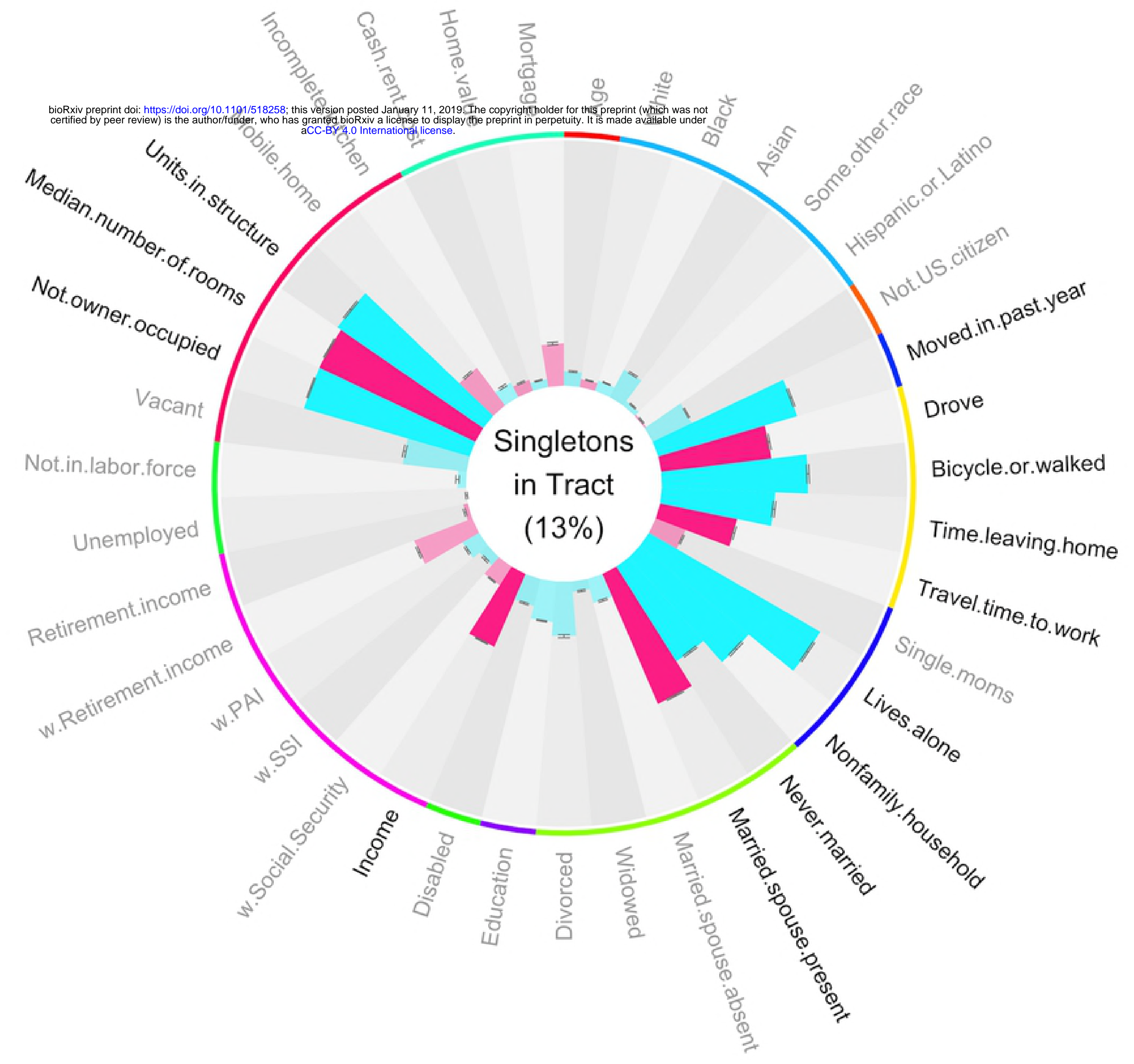

Fig S6B 


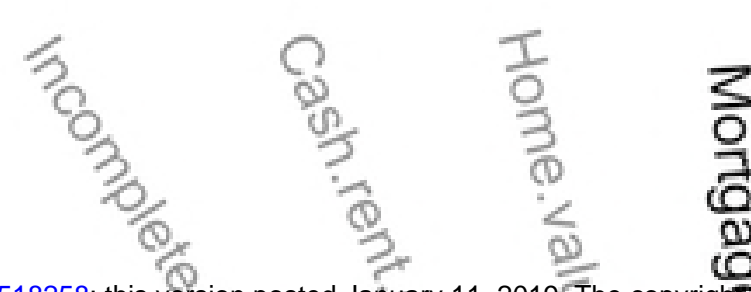

을

8

bioRxiv preprint doi: https://doi.org/10.1101/518258; this version posted January 11, 2019 The co

certified by peer review) is the author/funder, who has granted bioRxiv a license to display the preprint in perpetuity. It is made available under

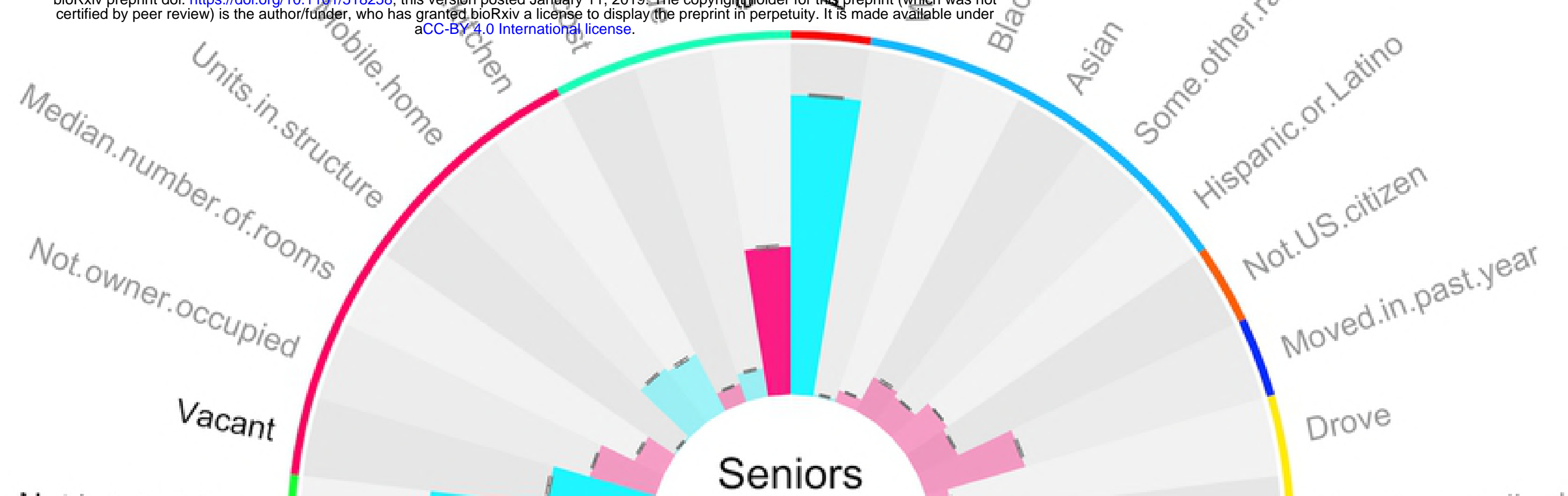

\section{Not.in.labor.force}

Unemployed

Retirementincome We Retirementincome

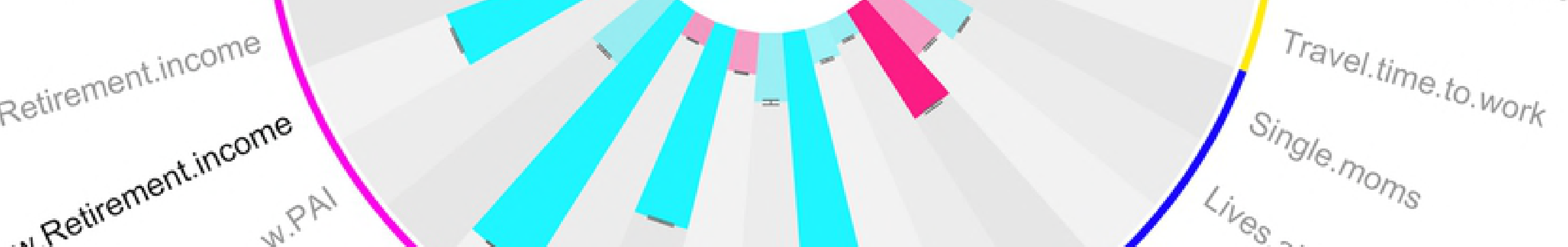

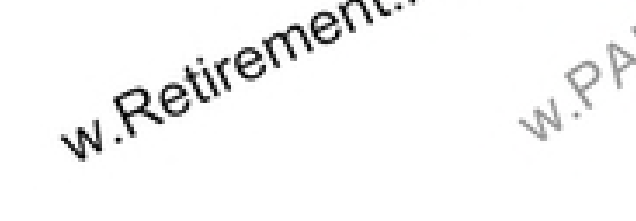

\section{Fig S6C}




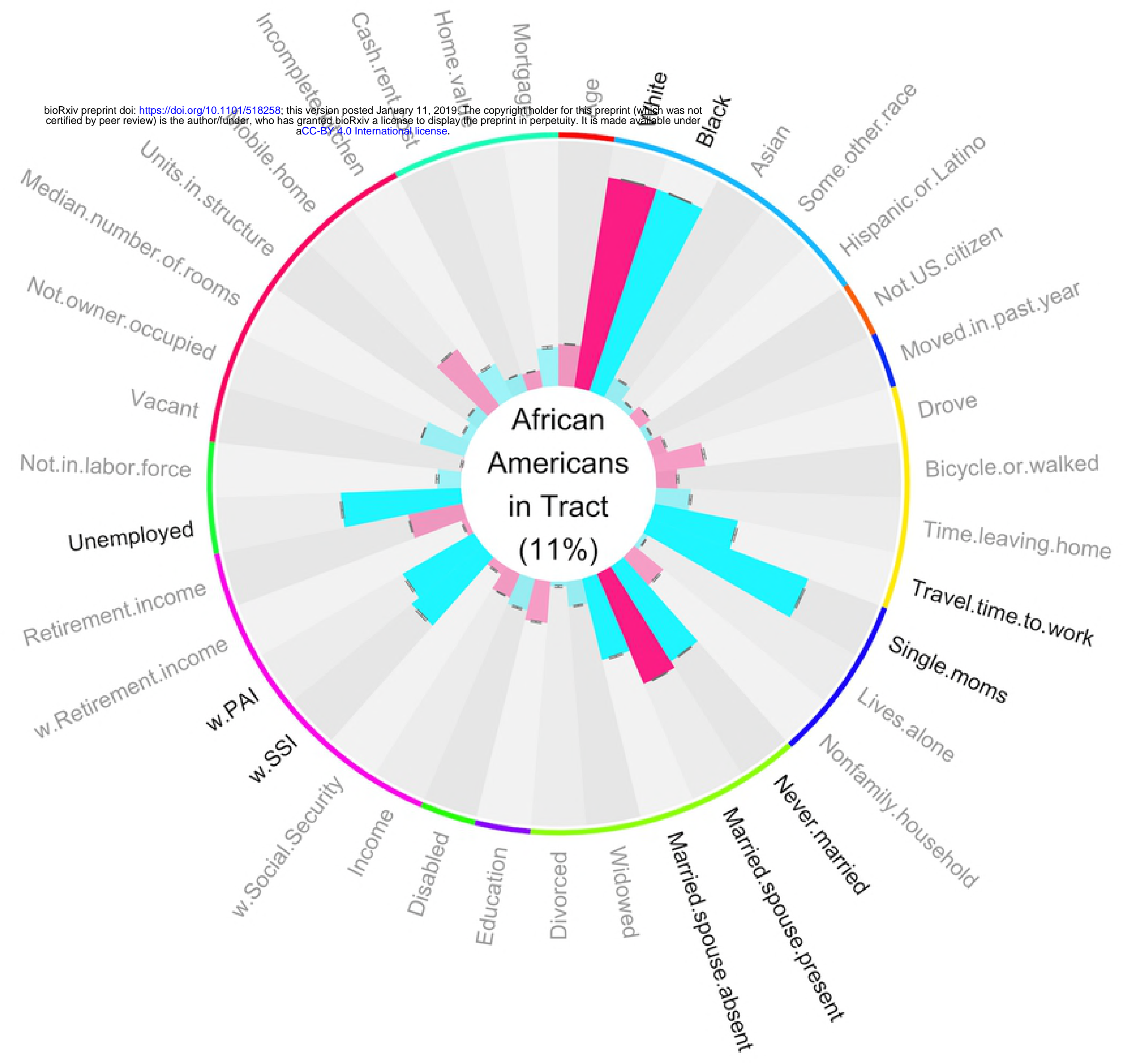

Fig S6D 


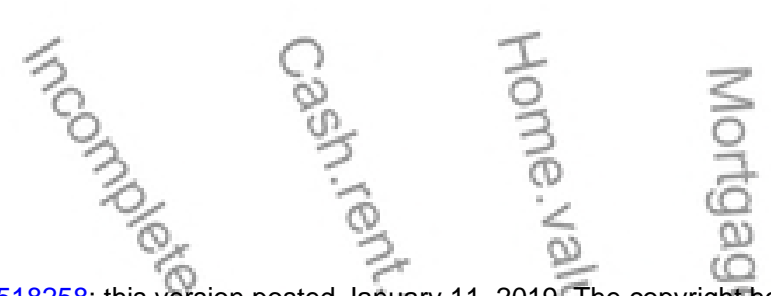

$\stackrel{9}{\approx}$

bioRxiv preprint doi: https://doi.org/10.1101/518258; this version posted January 11, 2019. The copyrightholder for this preprint (which was not certified by peer review) is the author/funder, who has granted bioRxiv a license to display the preprint in perpetuity. It is made available under
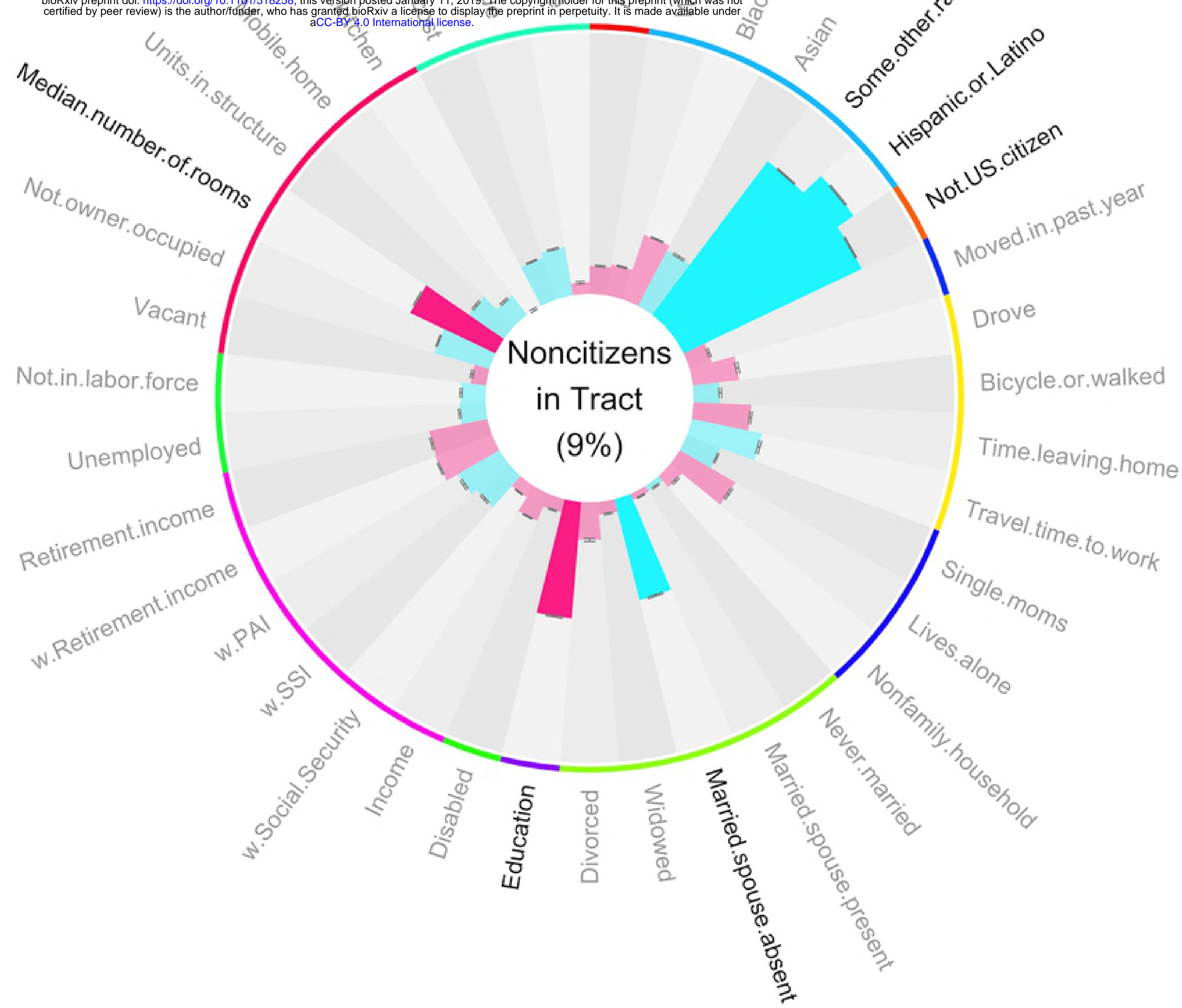

Fig S6E 
Affluence Singletons in Tract Seniors in Tract African Americans in Tract Noncitizens in Tract

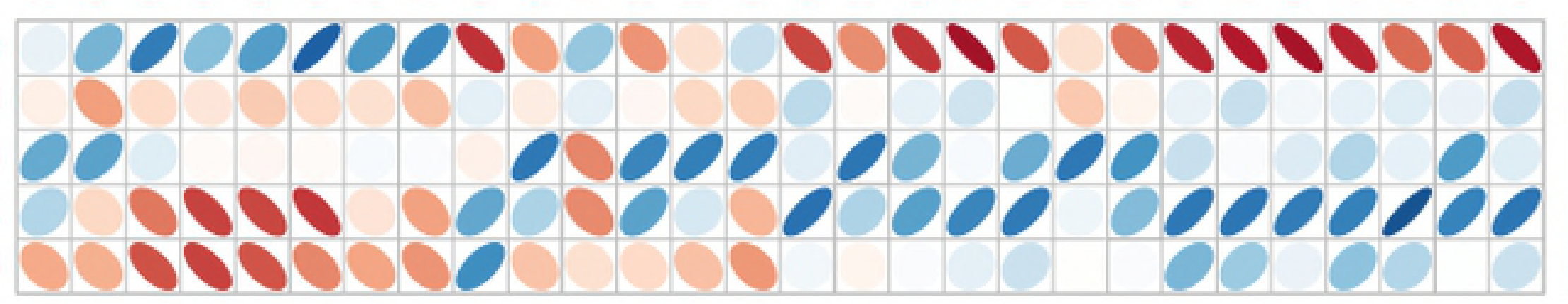

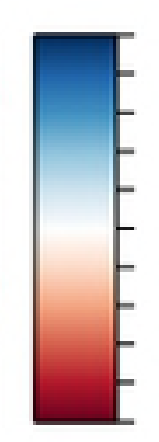

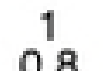

0.6 0.4 0.2 $-0.2$ $-0.4$ $-0.6$ $-0.8$

Fig S9 


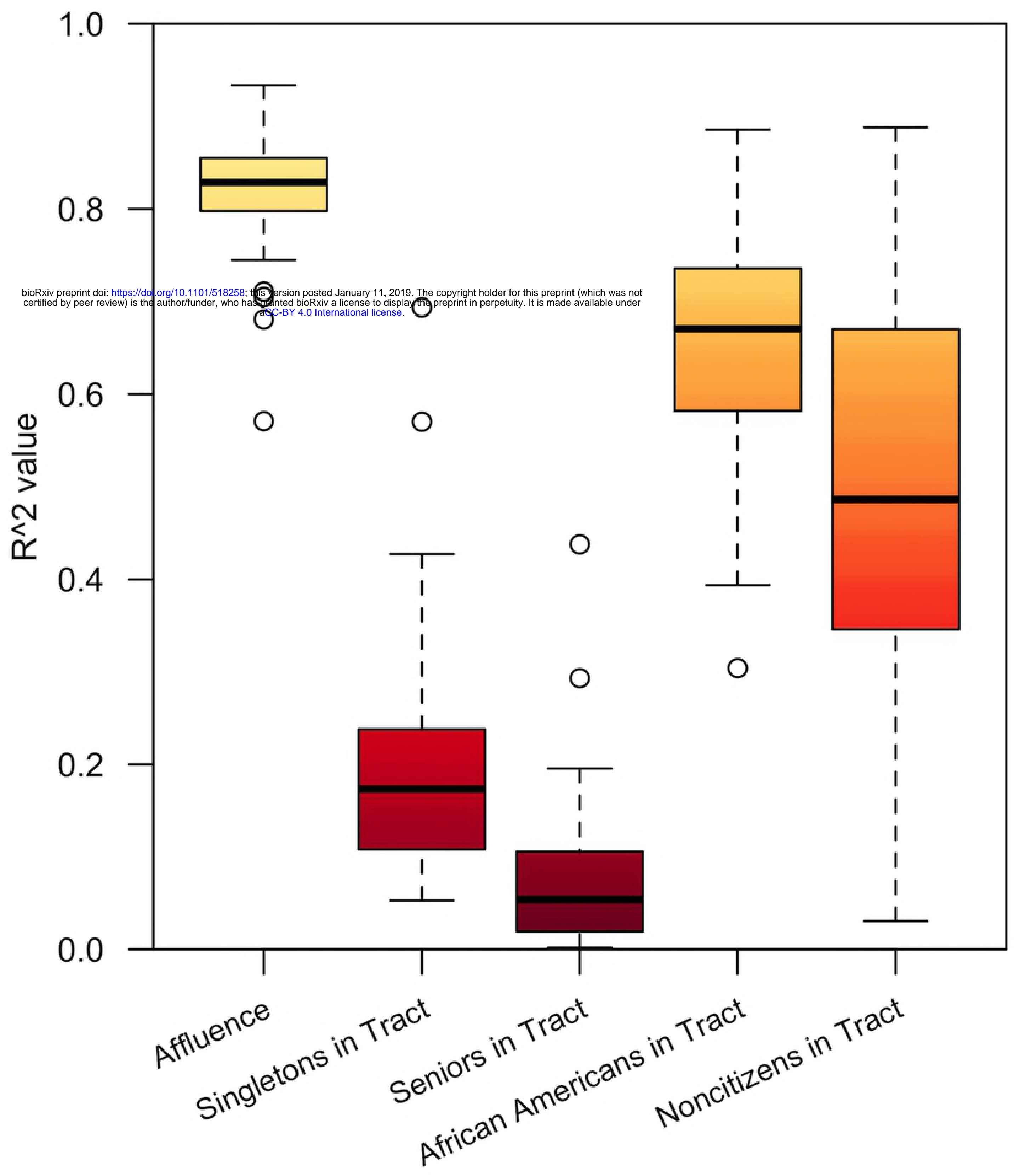

Fig S8 